\title{
Phased Array-Fed Reflector (PAFR) Antenna Architectures for Space-Based Sensors
}

\author{
Michael Cooley \\ Northrop Grumman Electronic Systems \\ 7323 Aviation Blvd. - MS 125 \\ Baltimore, MD 21240 \\ 410-993-3528 \\ Michael.cooley@ngc.com
}

\begin{abstract}
Communication link and target ranges for satellite communications (SATCOM) and space-based sensors (e.g. radars) vary from approximately $1000 \mathrm{~km}$ (for LEO satellites) to $\mathbf{3 5 , 8 0 0} \mathrm{km}$ (for GEO satellites). At these long ranges, large antenna gains are required and legacy payloads have usually employed large reflectors with single beams that are either fixed or mechanically steered. For many applications, there are inherent limitations that are associated with the use of these legacy antennas/payloads.
\end{abstract}

Hybrid antenna designs using Phased Array Fed Reflectors (PAFRs) provide a compromise between reflectors and Direct Radiating phased Arrays (DRAs). PAFRs provide many of the performance benefits of DRAs while utilizing much smaller, lower cost (feed) arrays. The primary limitation associated with hybrid PAFR architectures is electronic scan range; approximately +/-5 to $+/-10$ degrees is typical, but this range depends on many factors. For LEO applications, the earth FOV is approximately +/-55 degrees which is well beyond the range of electronic scanning for PAFRs. However, for some LEO missions, limited scanning is sufficient or the CONOPS and space vehicle designs can be developed to incorporate a combination mechanical slewing and electronic scanning.

In this paper, we review, compare and contrast various PAFR architectures with a focus on their general applicability to space missions. We compare the RF performance of various PAFR architectures and describe key hardware design and implementation trades. Space-based PAFR designs are highly multi-disciplinary and we briefly address key hardware engineering design areas. Finally, we briefly describe two PAFR antenna architectures that have been developed at Northrop Grumman.

\section{TABLE OF CONTENTS}

1. INTRODUCTION .1

2. PAFR ARCHITECTURES .........................1

3. PAFR DESIGN AND TECHNOLOGIES .7

4. PAFR HARDWARE EXAMPLES .............8

5. CONCLUSION .............................................10

REFERENCES................................................10

BIOGRAPHY ...................................................10

ACKNOWLEDGEMENTS ...............................11

\section{INTRODUCTION}

This paper has 3 major sections covering PAFR architectures (Section 2), associated hardware and technologies (Section 3) and two relevant PAFR design examples (Section 4). Section 2 reviews various PAFR architectures and provides a relative comparison of fundamental architectural features and associated performance trades. We compare the RF performance of various PAFR architectures, compare associated array feeds and describe key architecture and implementation trades. Section 3 focuses more on reflector and feed array hardware design including a discussion of technology options and associated trades. Space-based PAFR designs are highly multi-disciplinary and we will briefly address key engineering design areas including; antenna, RF electronics, DC power and beam steering control, mechanical, thermal, etc. Finally, in Section 4, we briefly describe two PAFR antenna architectures that have been developed at Northrop Grumman; a PAFR using dual confocal paraboloidal reflectors that was demonstrated under IR\&D and a Cassegrain PAFR with a reflector/reflectarray surface that is under development for NASA as part of an instrument technology development risk reduction program [1,2].

\section{PAFR ARCHITECTURES}

The architecture and design trades associated with PAFR architectures for space applications are generally complex and highly interdisciplinary. Given that most space-based PAFRs are physically large, a wide range of highly disparate design drivers and technical concerns must be balanced and traded. These include:

- Overall RF sensor system performance, i.e. radar or communication system metrics

- PAFR sub-system RF performance, e.g. electronic scanning, EIRP, G/T, beamwidth, sidelobes, etc.

- S/C accommodation of PAFR hardware

- Mechanical interfaces

- Stowed and deployed volumes/envelopes

- S/C electrical interfaces; RF, control/data, power

- Mechanical/environmental design

- Vibration, acoustic

- Thermal/cooling

- Atomic oxygen, radiation exposure

- SWAP

- Cost 
Balancing these diverse requirements and design drivers demands a detailed comparison and assessment of various candidate PAFR architectures. The following 3 SubSections summarize the associated architecture and design trade considerations; Sub-Section A outlines the various candidate PAFR architectures, Sub-Section B discusses typical mission/sensor requirements, and Sub-Section C provides a brief description of the associated trades.

\section{A. Architectural Options/Features}

Table 2.1 summarizes typical PAFR and feed array architectures. These various architectures are discussed in the literature; reflectors [3,4,5], feed arrays and beamforming $[6,7,8]$, and PAFRs [9,10]. The reflector architectures are categorized as employing either a spherical wave feed type (direct-fed and Cassegrain) or plane wave feed type (confocal).

The candidate feed architectures include various analog technologies and approaches such as AESA/corporate, Butler matrices, Rotman lenses, etc. Strictly speaking, switched beam array architectures using Butler matrices and Rotman lenses might not be considered "phased arrays". However, these feed architectures are array based and employ a variety of methods of RF/electronic control for PAFR beam forming. In this paper, we apply a broad PAFR definition, and these architectures are included. Digital beamforming architectures offer significant performance advantages and their usage is proliferating in direct radiating AESA systems. This is highly enabling for PAFR systems.

Table 2.1 Summary/Comparison of PAFR and Associated Array Feed Architectures

\begin{tabular}{|c|c|c|c|}
\hline $\begin{array}{l}\text { Feed Wavefront } \\
\text { Type }\end{array}$ & $\begin{array}{c}\text { Reflector } \\
\text { Architecture(s) }\end{array}$ & $\begin{array}{l}\text { Feed Architecture } \\
\text { Candidates }\end{array}$ & Description \\
\hline \multirow{4}{*}{ Spherical Wave } & \multirow{4}{*}{$\begin{array}{l}\text { - Direct-Fed } \\
\text { Parabolic } \\
\text { - Cassegrain } \\
\text { - Parabolic Cylinder } \\
\text { (Direct Fed or } \\
\text { Cassegrain) }\end{array}$} & $\begin{array}{l}\text { Weighted Analog AESA } \\
\text { (Corporate Feed) }\end{array}$ & $\begin{array}{l}\text { - Amplitude weighing "spot", "spot" moves to scan beam } \\
\text { - Includes center-fed and offset-fed geometries } \\
\text { - Includes de-focused feed variants (can use CFM to determine } \\
\text { feed amp/phase weights) }\end{array}$ \\
\hline & & Weighted DBF AESA & $\begin{array}{l}\text { Similar to Weighted Analog AESA PAFR architecture, but enables } \\
\text { higher beam counts }\end{array}$ \\
\hline & & Butler Matrix & $\begin{array}{l}\text { - Designed with beam ports mapped to "spherical waves" } \\
\text { - Includes center-fed and offset-fed geometries } \\
\text { - Includes de-focused feed variants (can use CFM to determine } \\
\text { feed amp/phase weights) }\end{array}$ \\
\hline & & Switch Matrix & $\begin{array}{l}\text { - Turn on-off single feed elements to scan beam } \\
\text { - Parabolic cylinder - turn on-off feed rows or feed columns to } \\
\text { scan beam }\end{array}$ \\
\hline \multirow{4}{*}{ Plane Wave } & \multirow{4}{*}{$\begin{array}{l}\text { - Confocal } \\
\text { - Parabolic Cylinder } \\
\text { (Confocal) }\end{array}$} & $\begin{array}{c}\text { Classic AESA } \\
\text { (Corporate Feed) }\end{array}$ & Employ corporate feed architecture with single or multiple beams \\
\hline & & DBF AESA & Employ corporate DBF feed architecture with multiple beams \\
\hline & & Rotman Lens & $\begin{array}{l}\text { - 1D or 2D stacked lens variants depending on scan requirements } \\
\text { - 1D lens variant for confocal parabolic cylinder }\end{array}$ \\
\hline & & Butler Matrix & Designed with beam ports mapped to "plane waves" \\
\hline
\end{tabular}

Direct center-fed and offset PAFR architectures, such as those shown in Figure 2.1, are the most fundamental. These architectures employ a single parabolic reflector allowing high gain transmit (receive) collimation/focusing of spherical wave energy from (to) a focal point (i.e. feed) to a plane wave (i.e. antenna beam). The offset design is frequently preferred as it has no blockage. For PAFRs, this is a significant advantage since PAFR feeds are physically larger than conventional feeds. Furthermore, offset PAFRs feeds can typically be packaged directly on space vehicle precluding the need for large tower structures or deployments. PAFR feed sub-systems have complex electrical, mechanical interfaces and design requirements and the advantages associated with simplified packaging and interfaces are very significant. Figure 2.1 also shows how the PAFR feed can axially de-focused. The associated rationale and advantages are described later.

Cassegrain PAFR architectures, as shown in Figure 2.2, are similar in principal to direct-fed parabolic reflector architectures. However, Cassegrain architectures employ a additional (secondary) hyperbolic reflector which allows for re-positioning of the feed. This so-called "folded optics" associated with the Cassegrain design has some inherent packaging advantages, especially for center-fed architectures. Feed array defocusing can also be applied in Cassegrain PAFR architectures; its application is generally similar to that of direct fed PAFRs. Feed blockage and/or feed/subreflector interactions can be a concern for some Cassegrain PAFRs and designs must be developed with this in mind.

As mentioned above, PAFR feed arrays can be re-positioned or "de-focused" to spread the power over a larger feed area. The effects of defocusing are mitigated by adjusting the feed array amplitudes/phases. This design approach offers some important advantages.

For array transmit functionality, spreading the power over more elements in the array enables various design improvements/options. These include; 1) a higher potential total RF transmit power (higher EIRP), 2) more technology options for RF transmit power generation (e.g. various solid state MMIC technologies in lieu of a single TWTA or MPM), 3) simplification of the array thermal/cooling design 


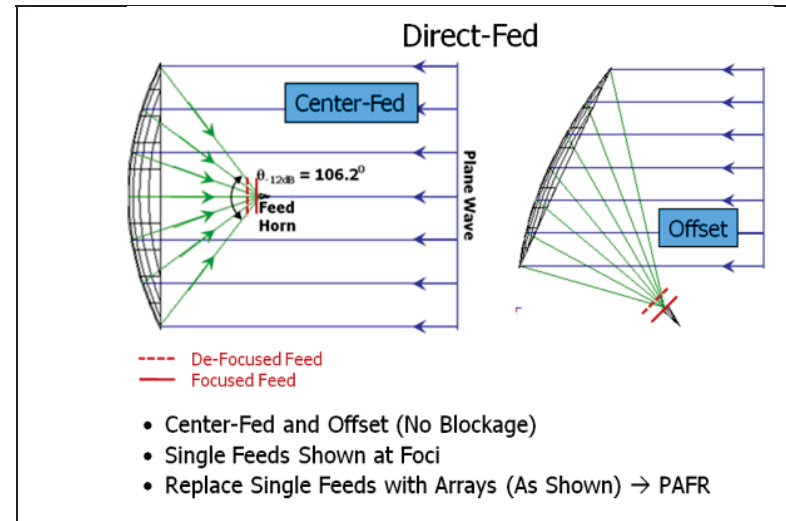

Figure 2.1 Direct-fed PAFR architectures; center-fed, offset.

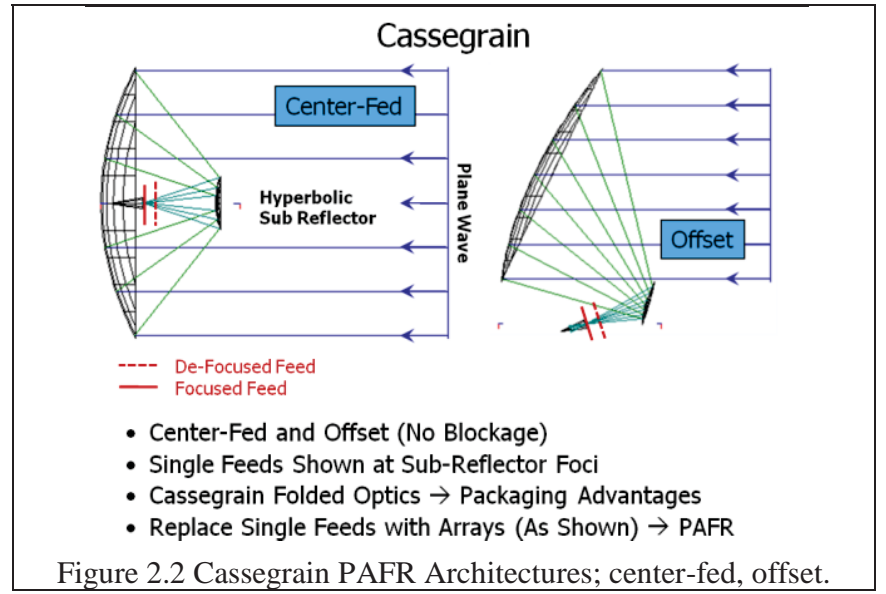

(due to lower concentrations of RF power), and finally 4) spatial distribution drops the required peak RF power levels in the feed RF electronics thereby mitigating multipaction design concerns (a notable issue, especially at lower frequencies).

For array receive functionality, spreading the power over more elements in the array also enables design improvements/options primarily in the area front end EMI protection and second/third order intercept (SOI/TOI) design. De-focused PAFR architectures with spatially distributed incident RF power are inherently less susceptible to interference. In some cases, this may alleviate the need for front end limiters and/or allow for design/operation of front end RF LNAs with lower required DC power.
Finally, for electronic beam scanning, de-focusing provides the ability to more effectively utilize or capture field energy and make feed amplitude/phase weighting adjustments to significantly reduce scan losses and beam distortion.

Figure 2.3 provides some relevant results from a parametric analysis to highlight the potential transmit design impacts and advantages of feed de-focusing. The PAFR architecture that was studied/analyzed uses an offset-fed parabola with a 187.5" diameter circular projected aperture and a focal length to diameter ratio (f/D) of 0.46. The feed array is a square grid design with an element spacing of 0.195 inches $(0.64 \lambda$ at $38.6 \mathrm{GHz})$. The array was parametrically defocused; 4 cases were analyzed with the array at the focus (reference) and de-focused (axially inward) by 2.57", 5.13" and 7.70".

The array synthesis and analyses were performed with a 2step process using GRASP software. In the first step, the array amplitude/phase weights are synthesized using the conjugate field matching (CFM) method [11,12] as illustrated in Figure 2.4. The GRASP-based physical optics (PO) scattering analysis incorporates an incoming (receive) incident plane wave source (broadside for the case shown in Figure 2.3) that is used to determine the complex E-fields at the feed array element locations. In the second step, these fields are conjugated and applied as the feed weights for a PO-based pattern analysis.

The results summarized in Figure 2.4 show that, as expected, the power spreads over the feed when it is defocused. The right column shows the utilized feed element count, assuming that elements with CFM synthesized amplitudes more than $10 \mathrm{~dB}$ below the peak are ignored. The utilized feed element increases from only 4 elements for the focused feed case to nearly 3500 elements for the 7.70 " de-focused feed case. The middle column captures the highest RF power per element (highest element amplitude across the feed array distribution) for the 4 cases (assuming normalization to $2 \mathrm{~kW}$ of total radiated RF power). This peak/highest power varies from 500W for the focused feed to $1.5 \mathrm{~W}$ for the 7.70 " de-focused feed. Figure 2.5 plots the results of the parametric feed de-focusing analysis showing how the feed amplitude distribution spreads out as the axial de-focusing is increased. This type of feed de-focusing informing PAFR architecture trade studies. 


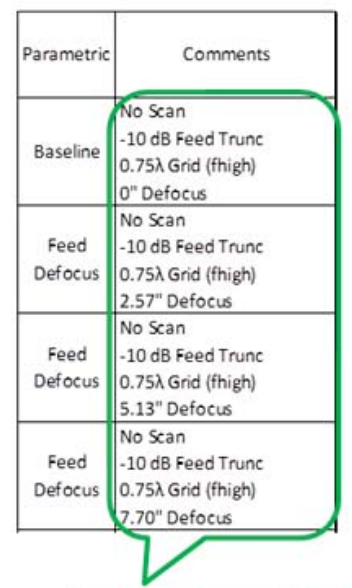

\section{Offset PAFR Study De-Focusing Study $-38.6 \mathrm{GHz}$}

\begin{tabular}{|c|c|c|}
\hline $\begin{array}{l}\text { Peak RF Output Power Per Site (W) } \\
\text { Normalized to } 1 \mathrm{~W} \text { Total Radiated }\end{array}$ & $\begin{array}{c}\text { Peak RF Output Power Per } \\
\text { Site (W) } \\
\text { Assuming } 2 \mathrm{~kW} \text { Total }\end{array}$ & Number of Utilized Feeds \\
\hline 0.25008065 & 500.1613007 & 4 \\
\hline 0.007057664 & 14.11532824 & 368 \\
\hline 0.001625276 & 3.250551412 & 1552 \\
\hline 0.000772661 & 1.545321245 & 3488 \\
\hline
\end{tabular}

Feed Location Varies from 0 " (At

Focus) to 7.70" (Defocused Inward)

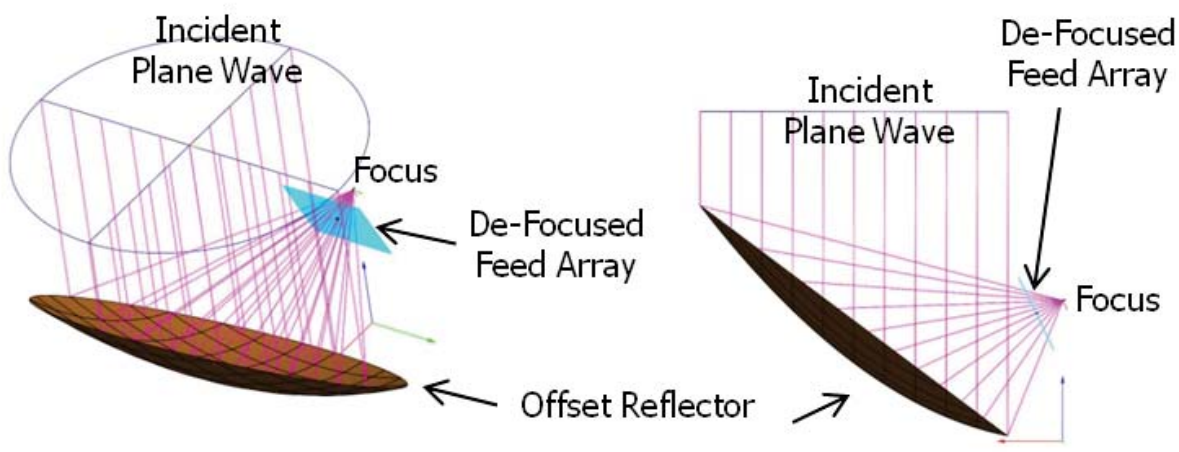

Figure 2.3 A sampling of results from an offset, direct-fed PAFR feed defocusing study (38.6 GHz)

\section{CFM Process}

Calculate Plane Wave Induced Fields at Desired Feed Location

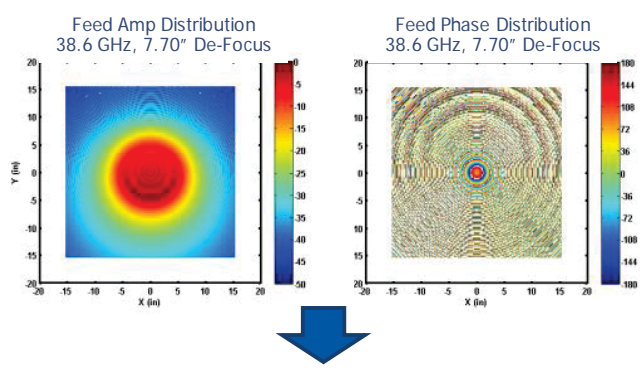

Conjugate Fields to Get Feed Excitation Weights $\rightarrow$ Compute Far-Field Pattern

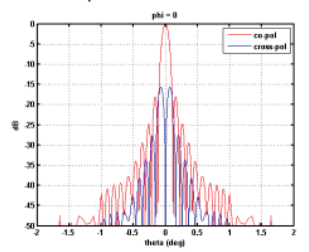

Figure 2.4 Conjugate Field Matching (CFM) process for PAFR feed array amplitude/phase synthesis.
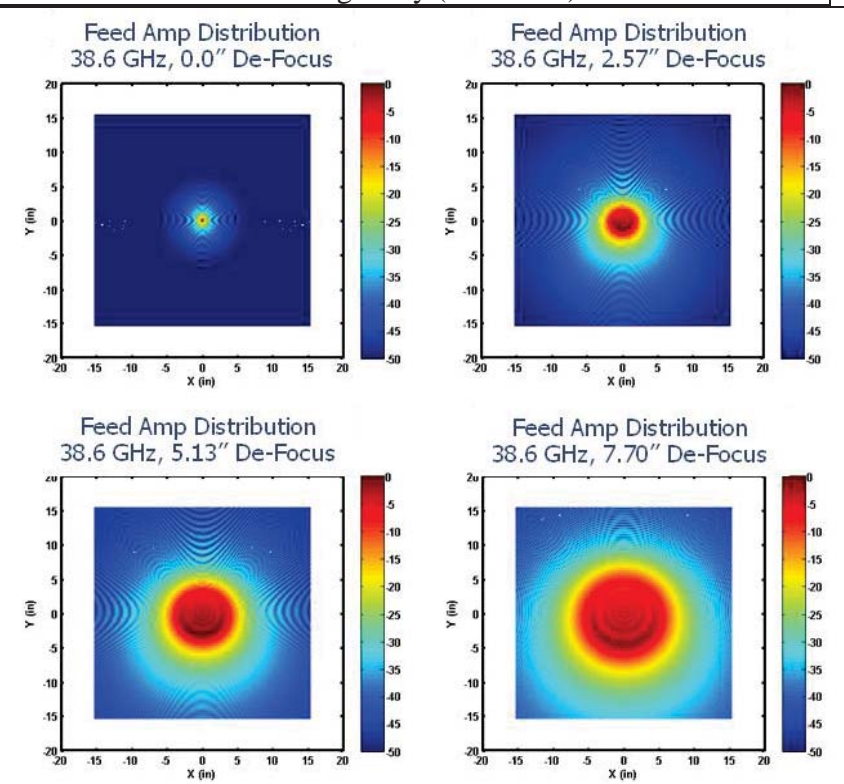

Figure 2.5 PAFR feed defocusing, feed amplitude distribution plots for 0", 2.57", 5.13" and 7.70" axial de-focus cases. 
The confocal PAFR architecture is fundamentally different from the previously discussed PAFR architectures $[13,10]$. As shown in Figure 2.7, the confocal PAFR architecture utilizes a pair of parabolic reflectors with different focal lengths. The parabolas are arranged such that their 2 foci share a common location. The confocal reflector optics are such that an input plane wave input (this represents the feed array from a transmit perspective) is "magnified" to an output plane wave (the antenna beam). The magnification factor $\mathrm{M}$ is the ratio of the focal lengths of the 2 reflectors and this factor typically ranges from $\sim 5$ to $\sim 15$. This architecture is essentially an AESA "magnifier"; a feed using a classical (plane wave based) AESA with a flat phase distribution (or a linear phase distribution for scanned beam) and magnifies the directivity/gain by $\mathrm{M}^{2}$. With $\mathrm{M}=10$, the directivity/gain of the feed will be increased by $20 \mathrm{~dB}$. The price paid for this directivity/gain magnification is electronic scan compression; if the feed is scanned $\theta$ degrees, the secondary beam will be scanned only $\theta / \mathrm{M}$ degrees. The results of a Northrop Grumman confocal reflector IR\&D design/development effort are briefly described in Section 4.

This Sub-Section has provided a succinct summary of the primary PAFR architectures. However, the discussion was certainly not comprehensive in nature. There are a variety of other PAFR and reflector technologies that have not been addressed herein. Some of the more relevant examples of topics not addressed herein include:

- Gregorian reflector architectures

- Axially displaced ellipse (ADE) architectures

- Beam waveguides

- Frequency selective surfaces (FSSs)

- Lenses

- Passive, printed circuit reflectarrays

While not described in detail herein, FSS and printed circuit reflectarray technologies are a key part of the NASA Aerosol, Climate, Ecosystem (ACE) mission Technology Development effort described in Section 4.

PAFRs are generally employed to enable limited electronic scan and/or multi-beam operation with spatially distributed (e.g. switched) beams. However, in some cases, PAFR designs are considered due to inherent advantages associated with high power RF transmission. These advantages include:

- Increased potential RF transmit power (higher EIRP) due to spatial combining

- Enables solid state RF transmitter options (various MMIC technologies)

- Simplifies thermal design (inherent power spreading)

- At lower frequencies (S-band and below)

- Mitigates multipaction (spatial power distribution reduces peak power levels within RF front end)

- Enables low profile feed arrays, reduces size/weight

Figure 2.8 highlights a high power radar application that benefits from the use of a PAFR design with a small array feed. This offset direct-fed multi-function reflector design incorporates 4 discrete bands for both communication and remote sensing. The S-band radar feed utilizes a 7-element planar array feed (PAFR) and provides very high RF transmit power and EIRP levels and offers all of the advantages cited above.

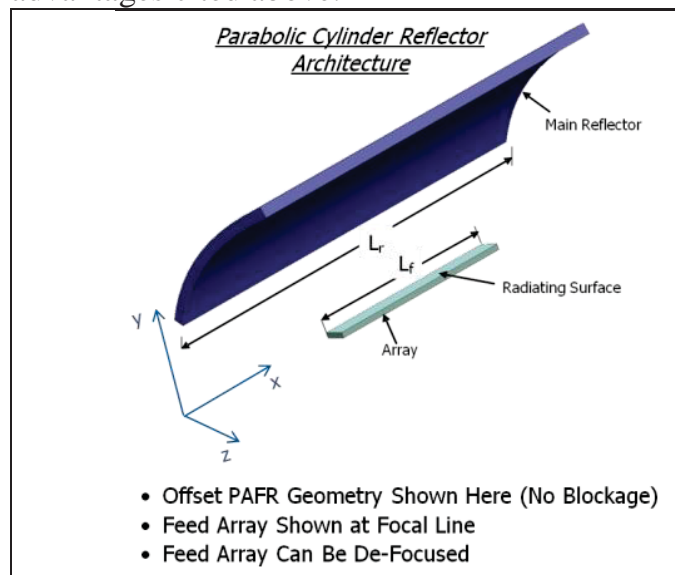

Figure 2.6. The offset linear PAFR architecture is well suited for applications requiring $1 \mathrm{D}$ electronic scanning over larger angular ranges.
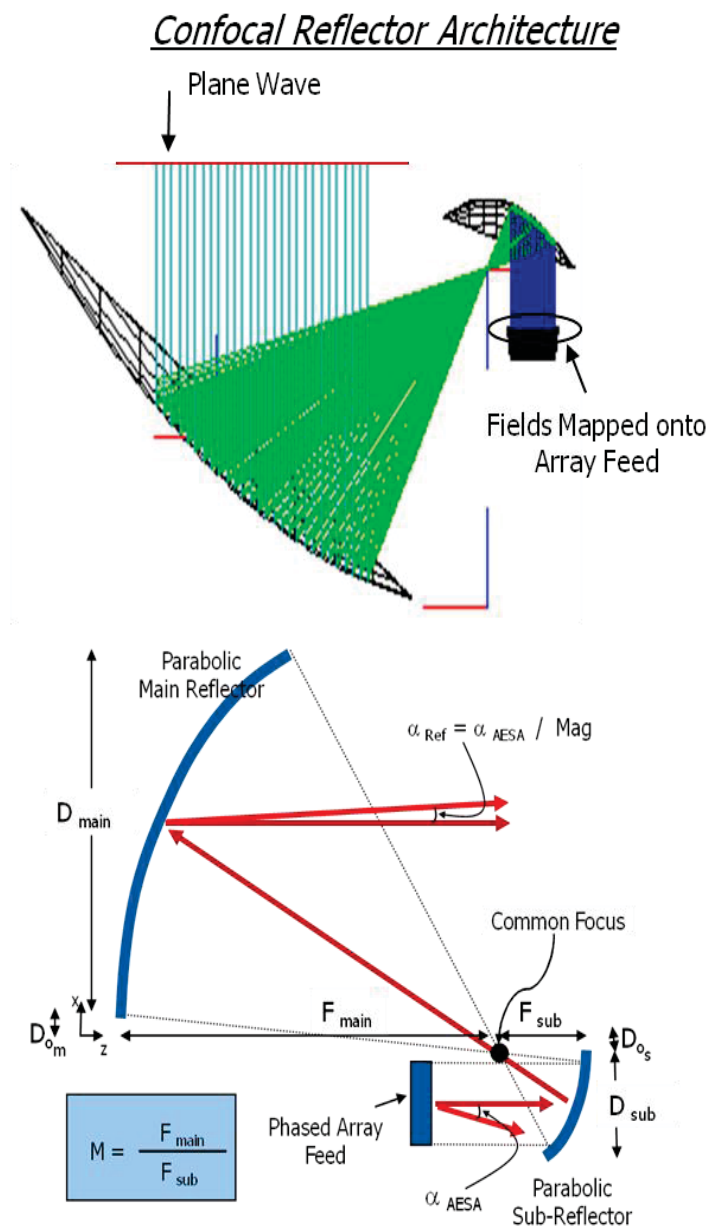

Figure 2.7 Confocal PAFR architecture; geometry and associated ray optics. 


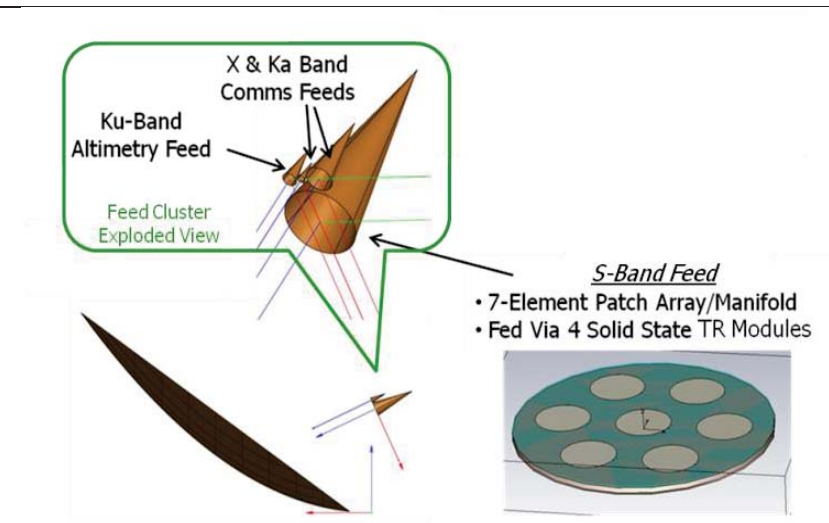

Figure 2.8 Example of PAFR use for a non-electronic scanning application; PAFR offers other advantages that stem from the spatial distribution of RF power.

\section{B. Driving Mission/Sensor and PAFR Requirements}

Most existing and heritage LEO communication and radar systems provide either slewed/scanned antenna beams to meet mission requirements. In many cases, scanned beam operation is achieved via spacecraft slewing or antenna gimbaling [10]. However, for some communication and radar systems, mechanical scanning drives the space vehicle agility or gimbal mechanism cost/complexity. In such cases, PAFR designs substantially alleviate these vehicle and gimbal design challenges and/or offer significant performance advantages.

Many of today's GEO communication systems provide multi-beam clusters to enhance capacity $[14,15,16]$. Most of these systems employ PAFRSs (or switched beam array feeds that have similar hardware functionality). The PAFR architecture discussions in Section 2 of the paper are generally applicable to these switched beam GEO systems. And, most of the hardware centric technology discussion in Section 3 is also applicable.

Table 2.2 lists the primary mission/sensor requirements drive the choice to use PAFR architectures. These critical requirements that drive the use of PAFRs are field of view (FOV), scan rate, EIRP, and simultaneous beam count.

\section{Trade Considerations}

The descriptions and discussions included in Sections 1 and 2 illustrate the diversity of PAFR design options and the rich/complex trade space associated with PAFR design. When faced with a new RF mission/sensor development, the first questions that should be asked are fundamental; what type of architecture do I need? And, for systems requiring high antenna gain, the top level trade will boil down to reflector vs. PAFR vs. AESA (direct radiating). The decision should be based on a detailed requirements analysis followed by an architecture trade study. That said, the 3 primary design drivers that tilt the table toward PAFRs and AESAs are:

- FOV, Electronic Scan

- Simultaneous or Fast Operations, i.e. Beam Count

- Re-Configurability
Table 2.3 Key reflector design drivers/requirements.

\begin{tabular}{|c|c|c|c|}
\hline $\begin{array}{c}\text { Design } \\
\text { Driver }\end{array}$ & $\begin{array}{c}\text { Reflector } \\
\text { Design } \\
\text { Criteria }\end{array}$ & $\begin{array}{c}\text { Design } \\
\text { Values, } \\
\text { Choices }\end{array}$ & Comments \\
$\begin{array}{c}\text { Antenna } \\
\text { Gain/Aperture } \\
\text { Size }\end{array}$ & $\begin{array}{c}\text { Physical Size, } \\
\text { Solid } \\
\text { Composite vs. } \\
\text { Deployable } \\
\text { Mesh }\end{array}$ & $\begin{array}{c}\mathrm{G} \sim \varepsilon 4 \pi \mathrm{A} / \lambda^{2}, \\
\varepsilon \sim 0.6, \\
\mathrm{~A}=\text { aperture } \\
\text { area, } \lambda=\mathrm{RF} \\
\text { wavelength }\end{array}$ & $\begin{array}{c}\text { Tied to } \\
\text { frequency band } \\
\text { and gain reqt } \\
\text { (mission } \\
\text { driven) }\end{array}$ \\
\hline RF Frequency & $\begin{array}{c}\text { Surface } \\
\text { Accuracy, }\end{array}$ & $\sim \lambda / 40$ & $\begin{array}{c}\text { Approximately } \\
\lambda / 40 \text { rms error }\end{array}$ \\
\hline $\begin{array}{c}\text { Solerance } \\
\text { Fairing }\end{array}$ & $\begin{array}{c}\text { Stowed } \\
\text { Volume and } \\
\text { Mass }\end{array}$ & $\begin{array}{c}\text { Size, Weight, } \\
\text { Complexity } \\
\text { Trades }\end{array}$ & $\begin{array}{c}\text { Linked to S/C } \\
\text { and launch } \\
\text { vehicle/fairing }\end{array}$ \\
\hline $\begin{array}{c}\text { Mechanical } \\
\text { Scan/Slew } \\
\text { Rates }\end{array}$ & $\begin{array}{c}\text { Reflector and } \\
\text { Strut or Boom } \\
\text { Stiffness }\end{array}$ & $\begin{array}{c}\text { Fixed or } \\
\text { Deployable, } \\
\text { Structural } \\
\text { Design }\end{array}$ & \\
\hline $\begin{array}{c}\text { Electronic } \\
\text { Scan, RF } \\
\text { Power, }\end{array}$ & Reflector \\
Packaging, \\
Etc.
\end{tabular}

Space-based reflector hardware design for PAFRs is very briefly summarized later in Section 3. In this Section, we briefly cite some of the key design drivers/requirements (see Table 2.3).

Space-based array feed hardware design for PAFRs is very briefly summarized later in Section 3. In this Section, we briefly cite some of the key design drivers/requirements (see Table 2.4).

Table 2.4 Key array feed design drivers/requirements.

\begin{tabular}{|c|c|c|}
\hline Design Driver & $\begin{array}{c}\text { Array Feed Design } \\
\text { Criteria }\end{array}$ & $\begin{array}{c}\text { Design Values, } \\
\text { Evaluation }\end{array}$ \\
\hline RF Frequency & Array Grid Spacing & $\begin{array}{c}\sim 0.6 \lambda-0.9 \lambda, \lambda \text { is the RF } \\
\text { wavelength }\end{array}$ \\
\hline RF Bandwidth & $\begin{array}{c}\text { Array RF Design } \\
\text { Complexity }\end{array}$ & $\begin{array}{c}\text { Multi-octave designs are } \\
\text { stressing }\end{array}$ \\
\hline $\begin{array}{c}\text { Electronic Scan } \\
\text { Range }\end{array}$ & $\begin{array}{c}\text { Array Size for Direct- } \\
\text { Fed and Cassegrain, } \\
\text { Grid Spacing for } \\
\text { Confocal }\end{array}$ & $\begin{array}{c}\text { Physics differs } \\
\text { significantly for } \\
\text { direct/Cassegrain vs. } \\
\text { confocal }\end{array}$ \\
\hline $\begin{array}{c}\text { RF Transmit } \\
\text { Duty Cycle }\end{array}$ & $\begin{array}{c}\text { MMIC Technologies, } \\
\text { Thermal Design, } \\
\text { Advanced Packaging, } \\
\text { Feed De-Focusing } \\
\text { (Power Spreading) }\end{array}$ & $\begin{array}{l}\text { Stresses thermal design, } \\
\text { need close proximity to } \\
\text { S/C or thermal radiators }\end{array}$ \\
\hline $\begin{array}{c}\text { MMIC DC-RF } \\
\text { Budget }\end{array}$ & $\begin{array}{c}\text { Efficiency, Low Front } \\
\text { End Losses, Advanced } \\
\text { Packaging }\end{array}$ & $\begin{array}{l}\text { Modern amplifier } \\
\text { MMICs compete well } \\
\text { with TWTAs (especially } \\
\text { when front end losses } \\
\text { are considered) }\end{array}$ \\
\hline EMI & $\begin{array}{c}\text { Limiter Incorporation, } \\
\text { MMIC Technology, } \\
\text { Feed De-Focusing }\end{array}$ & $\begin{array}{l}\text { Power budget is a } \\
\text { constraint }\end{array}$ \\
\hline $\begin{array}{c}\text { Simultaneous } \\
\text { Beam Count }\end{array}$ & $\begin{array}{c}\text { Advanced Packaging, } \\
\text { Amp/Phase Control } \\
\text { MMICs, Digital } \\
\text { Beamforming (DBF) }\end{array}$ & $\begin{array}{l}\text { Beam count can drive } \\
\text { analog vs. DBF trade, } \\
\text { and switched beam } \\
\text { architecture } \\
\text { considerations } \\
\text { (potentially simpler in } \\
\text { some cases) }\end{array}$ \\
\hline
\end{tabular}


Table 2.2 Primary mission/sensor requirements that drive the choice to employ a PAFR design/architecture.

\begin{tabular}{|c|c|c|c|}
\hline Driving Reqt & $\begin{array}{l}\text { Typical Reqt } \\
\text { Values }\end{array}$ & Performance Advantage Provided By PAFR & Comments \\
\hline FOV & $\begin{array}{l}+/-3 \text { to }+/-10 \\
\quad \text { degrees }\end{array}$ & $\begin{array}{l}\text { Provides very fast (electronic) scanning or } \\
\text { simultaneous beam cluster over FOV }\end{array}$ & $\begin{array}{l}\text { - Beam scanning is typical for radar } \\
\text { - Beam cluster is typical for GEO } \\
\text { communications }\end{array}$ \\
\hline Scan Rate & $\begin{array}{l}100 \text { 's of ns to } \\
10 \text { 's of } \mu \mathrm{s}\end{array}$ & $\begin{array}{l}\text { Electronic scan rates provide enhanced coverage } \\
\text { (radar) or longer link intervals with greater pointing } \\
\text { stability (communications) }\end{array}$ & $\begin{array}{l}\text { Electronic scanning not only provides faster } \\
\text { scanning, but also enables non-raster } \\
\text { scanning, i.e. near instantaneous pointing to } \\
\text { desired look angles }\end{array}$ \\
\hline EIRP & $\begin{array}{l}\text { Varies } \\
\text { Widely }\end{array}$ & $\begin{array}{l}\text { PAFR feed array allows for sharing of transmitted } \\
\text { RF power across the array. Enables higher EIRP and } \\
\text { use of solid state amplifier technologies. }\end{array}$ & $\begin{array}{l}\text { PAFR architectures can also alleviate } \\
\text { multipaction design challenges by spatially } \\
\text { distributing the RF power and lowering peak } \\
\text { levels within the feed; a primary concern at } \\
\text { lower frequency bands, i.e. S-band and } \\
\text { below. }\end{array}$ \\
\hline $\begin{array}{l}\text { Simultaneous } \\
\text { Beam Count }\end{array}$ & $\begin{array}{l}\text { Varies } \\
\text { Widely }\end{array}$ & $\begin{array}{l}\text { PAFR feed array can be manifolded to provide } \\
\text { multiple beams. There are a variety of viable analog } \\
\text { and digital beamforming architectures. }\end{array}$ & $\begin{array}{l}\text { - Enables higher data collection rates and } \\
\text { larger fields of view for radar } \\
\text { - Enables multi-function sensor operations } \\
\text { and timelines if/when needed }\end{array}$ \\
\hline
\end{tabular}

\section{PAFR DESIGN AND TECHNOLOGIES}

As shown in Section 2, PAFRs consist of two major subsystems or sub-assemblies; 1 ) the reflector (or reflectors and its associated structures and stowage/deployment mechanisms, and 2) the array feed and associated RF electronics, local power supplies and thermal control features. In this Section we provide an very brief overview of these 2 major sub-systems and the associated technologies.

\section{A. Reflector Technologies}

Reflector technologies for space-based PAFRs fall into 2 general categories; 1) fixed or solid reflectors (generally composite construction), and deployable reflectors (these are typically mesh reflectors). Figure 3.1 shows and example of each of these technologies; a Northrop Grumman deployable ASTROmesh reflector [17] and a solid composite reflector (courtesy of Vanguard Space Technologies).

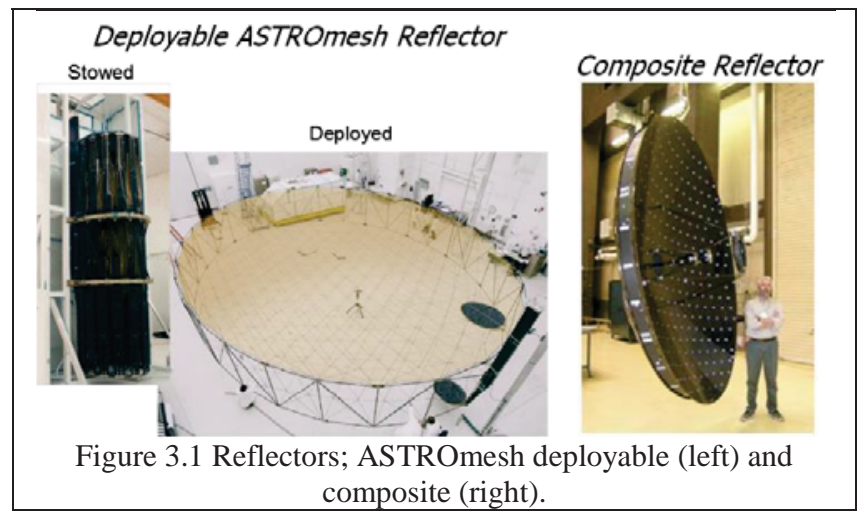

B. Array Feed Architectures and Technologies

A various of array feed beamforming architectures and technologies are described in $[6,7,8]$. PAFR beamformers can be categorized in various ways and in Table 2.1 we categorized these feeds according to the type of wavefront they need to generate (spherical or plane wave). Within these 2 broad categories, space-based PAFR beamformers can be architected using various technologies including analog AESA (e.g. T/R modules), corporate manifolds, constrained lenses (e.g. Rotman), Butler matrices, and digital beamforming. A wide variety of useful combinations of these technologies and design/architecture permutations can be applied depending on the specific RF sensor and system requirements. Figure 3.2 shows a few beamformer examples for illustration; an analog multi-beam AESA corporate feed, a digitally beamformed AESA corporate feed and a switched beam Rotman lens feed.

PAFR feeds are complex RF electronic sub-systems that employ a wide variety of complex technologies spanning a wide range of design disciplines. Figure 3.3 shows a conceptual design example; a Ka-band AESA linear feed for the planned NASA ACE radar. The primary PAFR subassemblies are briefly summarized in Table 3.1.

Table 3.1 Primary sub-assemblies, and associated technologies of PAFR feed arrays.

\begin{tabular}{|c|c|}
\hline $\begin{array}{c}\text { AESA } \\
\text { Sub-Assembly }\end{array}$ & Functional Role/Description \\
\hline Radiator/Aperture & $\begin{array}{l}\text { Couple RF energy from T/R } \\
\text { modules. Enables beam formation } \\
\text { and multiple polarizations, if } \\
\text { required. }\end{array}$ \\
\hline $\begin{array}{c}\text { T/R Modules or } \\
\text { Tiles }\end{array}$ & $\begin{array}{l}\text { HPAs (RF power), LNAs, } \\
\text { Amp/Phase Control. Multi-channel } \\
\text { options implemented as required. }\end{array}$ \\
\hline RF manifolds & Tx and Rx beamforming \\
\hline Rotman Lens & $\begin{array}{l}\text { Multi-beam passive beamformer } \\
\text { (applies to switched beam plane } \\
\text { wave architectures) }\end{array}$ \\
\hline Butler Matrix & $\begin{array}{l}\text { Multi-beam passive beamformer } \\
\text { (can be applied to spherical or } \\
\text { plane wave architectures) }\end{array}$ \\
\hline
\end{tabular}




\begin{tabular}{|c|l|}
\hline Power supplies & $\begin{array}{l}\text { Provides bias voltages and power } \\
\text { for various T/R module MMICs }\end{array}$ \\
\hline Switch Matrices & $\begin{array}{l}\text { As required by architecture, } \\
\text { especially significant for switched } \\
\text { beam architectures (e.g. Rotman) }\end{array}$ \\
\hline $\begin{array}{c}\text { A/D and D/A } \\
\text { Converters }\end{array}$ & $\begin{array}{l}\text { Required for digital beamforming } \\
\text { (DBF) feed architectures }\end{array}$ \\
\hline Thermal/Cooling & $\begin{array}{l}\text { Maintain MMIC junction } \\
\text { temperatures and remove heat from } \\
\text { feed array }\end{array}$ \\
\hline Structure/Packaging & $\begin{array}{l}\text { Encapsulate and package all } \\
\text { associated sub-assemblies and } \\
\text { components }\end{array}$ \\
\hline
\end{tabular}

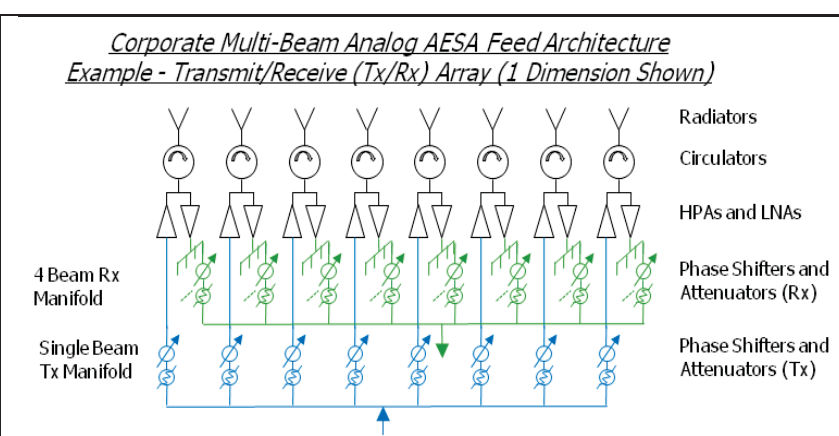

Corporate Multi-Beam Elemental DBF AESA Feed Architecture Example - 1D Transmit/Receive (TX/Rx) Array (1 Dimension Shown)

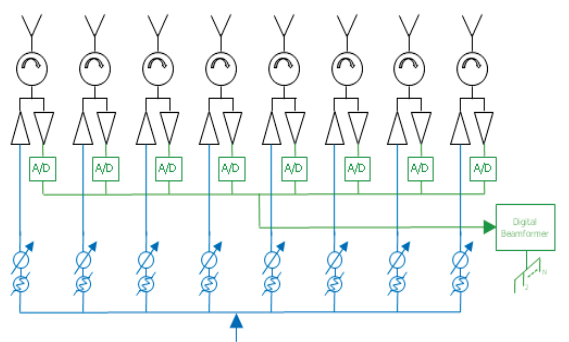

Rotman Lens BFN Feed Architecture Example-Receive (Rx) Array (1 Dimension Shown)

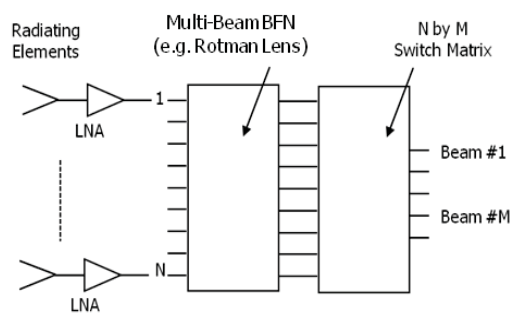

Figure 3.2 Common PAFR beamformer architectures; TOP analog corporate-fed AESA (multi-beam), MIDDLE - digitally beamformed corporate-fed AESA, BOTTOM - Rotman lens (switched beam).

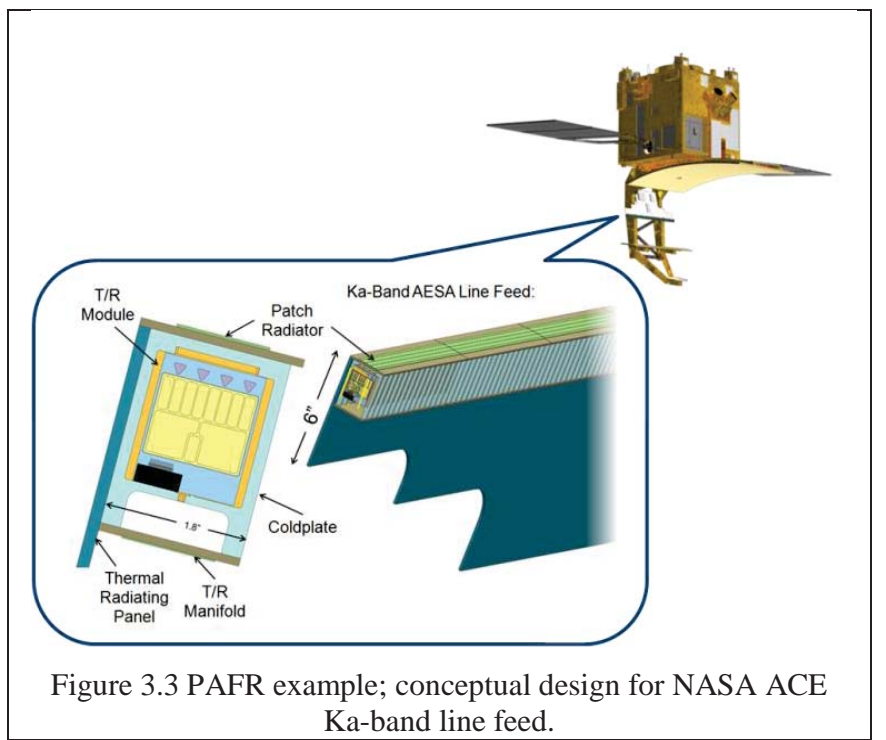

\section{PAFR HARDWARE EXAMPLES}

In this Section, we briefly describe two examples of NGES PAFR design/development activities. The $1^{\text {st }}$ example is a confocal reflector IR\&D demo (passive) that was conducted to study the beamforming and pattern synthesis/analysis of this type of architecture. The $2^{\text {nd }}$ example is a NASA sponsored $\mathrm{Ka} / \mathrm{W}$-band reflector/reflectarray technology development effort for the planned ACE satellite mission.

\section{A. Confocal Reflector Demonstration (NGC IR\&D)}

Figure 4.1 shows the NGC confocal IR\&D demo as configured for testing in the planar near field range. This $\mathrm{X}$ band demonstration utilized a 256 element passive array feed and a pair of parabolic reflectors. The two reflectors have 2 ' and 5 ' foot projected apertures and the focal length ratio (magnification factor) is 5:1. The passive array feed was configured to simulate scanning via 2 test methods. The $1^{\text {st }}$ method used the array with a broadside manifold; the array was then physically rotate along the elevation axis to generate a scanned feed wavefront. The $2^{\text {nd }}$ method used the array in an un-manifolded configuration; 256 single element patterns were collected and the desired beams were generated by applying complex weights and adding the patterns (superposition). For this test method, various pattern optimization methods were explored. Figure 4.2 captures a snapshot of some of the measured data; broadside contour patterns for the manifolded test configuration and a scanned beam pattern cut generated via element pattern superposition (with optimized weights). The agreement between the models and the measurements is quite good. 


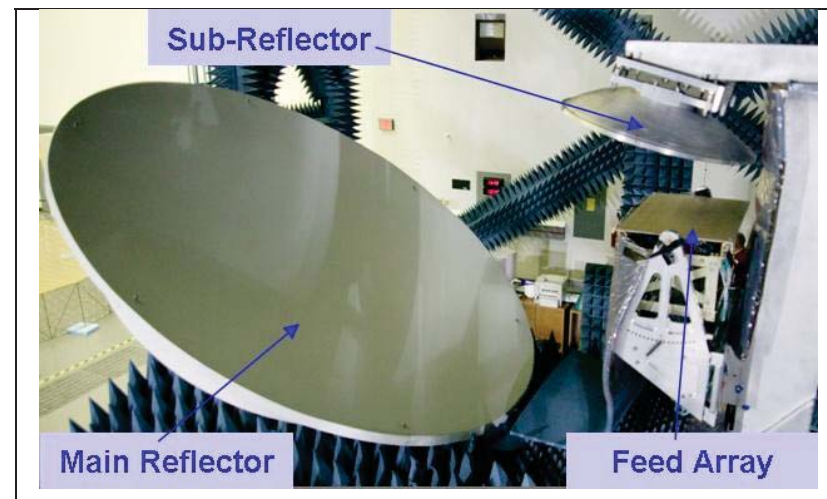

Figure 4.1 Confocal IR\&D; dual offset reflector demo in nearfield antenna range.

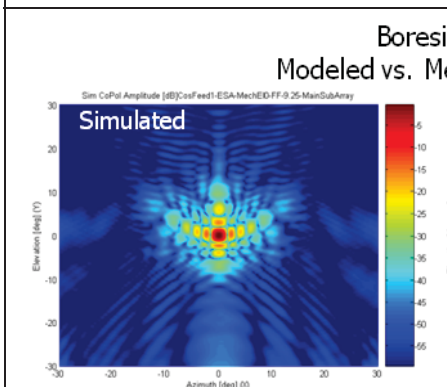

Boresite Beam

vs. Measured Patterns

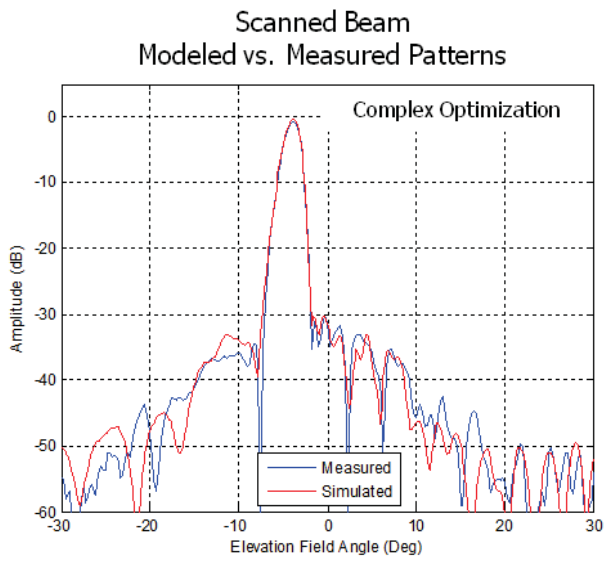

Figure 4.2 Confocal IR\&D; Measured vs. modeled patterns at Xband, TOP - boresite beam contours, BOTTOM - scanned beam pattern cut.

\section{B. Offset Direct-Fed Parabolic Cylinder (NASA ACE} Sub-Scale)

Figure 4.3 shows the NASA ACE sub-scale reflector/reflectarray antenna which is described in much more detail in $[1,2]$. This shared aperture dual-band radar (Ka/W-band) antenna architecture can enable significant SWAP and cost savings. The full scale aperture(s) needs to be 7-10 square meters and this architectures enables aperture sharing (eliminates a $2^{\text {nd }}$ large antenna structure).

This reflector/reflectarray architecture works as follows. The Ka-band employs a parabolic cylinder (Cassegrain for the full scale design) with an AESA line feed to enable 1D electronic scanning. The W-band uses a passive printed circuit reflectarray (applied to the parabolic cylinder reflector) to enable generation of a fixed pencil beam. The reflectarray collimates the energy to a single equivalent focal point ( $R F$ behavior is equivalent to a doubly curved parabola). The $\mathrm{W}$-band reflectarray surface is $\mathrm{RF}$ transparent at Ka-band and has no measureable impact (i.e. it's designed as an FSS at Ka-band). Figure 4.4 shows some pattern data and a gain/loss budget for the sub-scale antenna; the $\mathrm{W}$-band losses are quite low and the agreement between the models and the measurements is quite good.
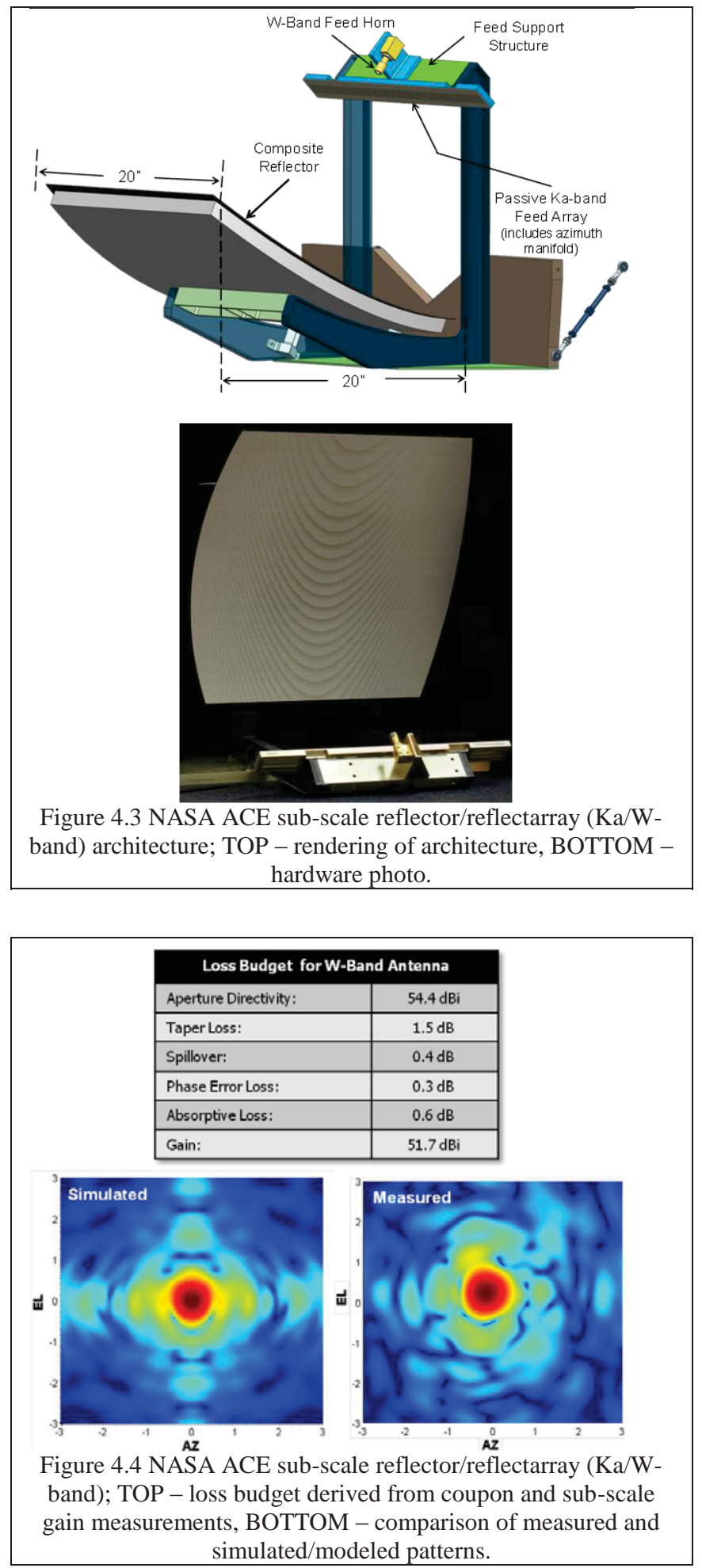


\section{CONCLUSION}

This paper has provided an overview of PAFRs and addressed their general applicability for space-based sensors. The paper has provided a broad overview of PAFR architectures, design trades and associated technologies (both feed and reflector). And, two relevant hardware examples were briefly described.

PAFRs are a "hybrid" antenna technology offering intermediate performance generally lying in between that of conventional reflectors and full-fledged 2D electronic scanning, direct radiating AESAs. For some missions, the PAFR capability is right-sized; i.e. it can offer more capability than a conventional reflector and less performance than that of a $2 \mathrm{D}$ AESA, but with a commensurate savings in SWAP/cost.

\section{REFERENCES}

1. M. E. Cooley, R. Park, P. Stenger, P. E. Racette, G. Heymsfield and L. Lu, "Dual-Band

Reflector/Reflectarray: A Novel Antenna Architecture for the NASA ACE Radar," AIAA Space Symposium, Long Beach, CA, Sept. 2011.

2. T. Hand, M. Cooley, G. Kempic, D. Sall, P. Stenger, S. Woodworth, R. Park, P. Racette, G. Heymsfield, L. Li "Designs, Technologies and Demonstrations for NASA's ACE Radar, Designs, Technologies and Demonstrations for NASA's ACE Radar," IEEE Phased Array Symposium on Phased Array Systems, Waltham, MA, 2013.

3. Johnson, R. C., and H. Jasik (Eds.), Antenna Engineering Handbook, $2^{\text {nd }}$ ed., McGraw-Hill Book Company, New York, pp. 32-11, 32-12, 1984.

4. Lo, Y. T., and S. W. Lee (Eds.), Antenna Handbook: Theory, Applications and Design, Reflector Antennas, Chapter 15, Van Nostrand Reinhold Co. Inc., 1988.

5. Rudge, A. W. and N. A. Adatia, "Offset Parabolic Reflector Antennas: A Review," Proceedings IEEE, vol. 66, no. 12, pp. 1592-1618, Dec. 1978.

6. P. S. Hall and S. J. Vetterlein, "Review of Radio Frequency Beamforming Techniques for Scanned and Multiple Beam Antennas," IEE Proceedings, vol. 137, Pt. H, No. 5, Oct. 1990.

7. Holzman and A. Agrawal, "A comparison of active phased array, corporate beamforming networks," IEEE Int. Symp. Phased-Array Technol., Boston, MA, Oct. 1996, pp. 429-434.

8. K. K. Chan and S. K. Rao, "Design of a Rotman Lens Feed Network to Generate a Hexagonal Lattice of Multiple Beams," IEEE Trans. Antennas and Propag., vol. 50, no. 8, pp. 1099-1108, Aug. 2002.
9. L. Shafai, M. Kehn and P. S. Kildal, "Parametric Characterization of Reflector Antennas Fed By Focal Plane Arrays," IEEE International Symposium Antennas and Propag., San Diego, CA, July, 2008.

10. M. E. Cooley and D. Davis, Chapter 12, "Reflector Antennas," Radar Handbook, M. Skolnik, (ed.), $3^{\text {rd }}$ Ed., New York, McGraw-Hill, 2008.

11. B. Saka and E. Yazgan, Pattern Optimization of a Reflector Antenna with Planar-Array Feeds and Cluster Feeds," IEEE Trans. Antennas and Propag., vol. 45, no. 1, pp. 93-97, Jan. 1997.

12. P. Lam, S. W. Lee, D. Chang and K. C. Lang, "Directivity Optimization of a Reflector Antenna with Cluster Feeds: A Closed Form Solution," IEEE Trans. Antennas and Propag., vol. 33, no. 11, pp. 1163-1174, Nov. 1985.

13. Ekelman, E. P. and B. S. Lee, “An Array-Fed, DualReflector Antenna System (of Offset Confocal Paraboloids) for Satellite Antenna Applications," IEEE Symp. Antennas Propag., pp.1586-1589, 1989.

14. J. Alexovich et. al., "The Hughes Geo Mobile Satellite System," Proceedings of the Fifth International Mobile Satellite Conference, Pasadena, CA, June 1997, pp. 159-165.

15. T. Chwalek et. al., "Recent Developments in Geo Mobile Antennas at Hughes Space and Communications," IEE Conference on Antennas and Propagation, Edinburgh, Scotland, April 1997.

16. C. Chandler, L. Hoey, D. Hixon, T. Smigla, A. Peebles and M. Em, "Ka-Band Communications Satellite Antenna Technology," 20 $0^{\text {th }}$ International AIAA Communication Satellite Systems Conference, Montreal, Quebec, Canada, May 2002.

17. Thomson, M., "The Astromesh Deployable Reflector," IEEE Symp. Antennas and Propag., pp. 1516-1519, 1999.

\section{BIOGRAPHY}

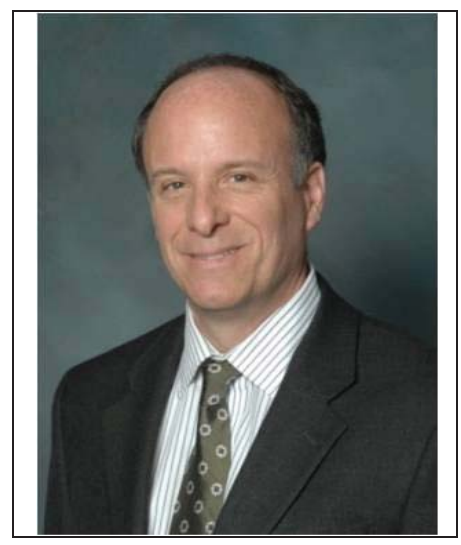

Michael Cooley is a Senior Consulting Engineer with Northrop Grumman Electronic Systems (NGES) in Baltimore, MD. He focuses on the development of antennas and $R F$ subsystems for radar, EW and communications. His experience and technical interests include AESAs, array-fed reflectors, reflectarrays and various associated technologies. 
He is currently working on antenna and RF sensor design and development for a variety of Programs, primarily in the Naval and Space domains.

Prior to joining NGES in 2003, Mike spent $~ 10$ years working primarily on space-based antenna systems at several other companies including Boeing Satellite Systems (formerly Hughes Space and Communications), Orbital Sciences Corp. and TASC, Inc. He earned his BSEE from the University of Maryland and his MSEE and PhD (EE) from the University of Massachusetts, Amherst.

\section{ACKNOWLEDGEMENTS}

I'd like to acknowledge Northrop Grumman Electronic Systems (NGES) for its support of the confocal IR\&D work cited in Section 4 and general support and review of this manuscript.

I'd also like to acknowledge the support of NASA's Earth Science Technology Office for its funding/support for the reflector/reflectarray work cited in Section 4. And, I'd like to recognize the collaboration and support of NASA Goddard staff members Paul Racette, Lihua Li, Gerry Heymsfield and Matt Mclinden.

Many of my colleagues within the RF/Antenna Department at NGES in Baltimore have also contributed to the work described herein. The contributions of John Wojtowicz, David Sall, Eric Holzman, John Thornton, Tom Hand, Gary Kempic, Tom Spence, Pete Stenger, Sarah Woodworth, Molly Finke and Richard Park are particularly noteworthy.

I'd also like to thank my colleagues at Northrop Grumman Aerospace Systems (Redondo Beach, CA) for their assistance and collaboration on the confocal IR\&D work. 